\title{
IS ANTENATAL CLINIC ATTENDANCE A PROXIMATE DETERMINANT OF USE OF MODERN HEALTHCARE FACILITY FOR DELIVERY BY NIGERIAN WOMEN?
}

\author{
Fasina F. Fagbeminiyi ${ }^{1 *}$, Gbolahan A. Oni ${ }^{2}$ \\ ${ }^{1}$ Department of Demography and Social Statistics, Covenant University, Ota, Ogun State, Nigeria \\ niyi.fasina@covenantuniversity.edu.ng \\ ${ }^{2}$ Department of Demography and Social Statistics, Covenant University, Ota, Ogun State, Nigeria \\ Gbolahan.oni@covenantuniversity.edu.ng \\ ${ }^{*}$ Corresponding Author
}

\begin{abstract}
A proximate determinant of an outcome (or event) is a variable (or factor) that produces a direct effect on that outcome. It can act as an intermediary variable through which other variables (or factors) which have indirect effects on the same outcome variable operate to exhibit their effects. Socioeconomic, demographic and cultural factors (also called background or underlying factors) are known to have indirect effects on whether or not a pregnant woman would choose to deliver her baby in a healthcare facility. The background or underlying factors of the women can also determine if they will attend or not attend antenatal clinic during pregnancy. However, antenatal clinic attendance also has direct effect on a woman's use of healthcare facility to deliver her baby.

In this study we examined whether or not antenatal clinic attendance is a major proximate determinant of use of healthcare facility for delivery by Nigerian women. However, the study shows that antenatal care visits had a very strong direct effect on mothers' delivery in healthcare facilities. The study used quantitative data from the 2008 Nigeria Demographic and Health Surveys (NDHS).Mothers were asked to indicate where they delivered their last babies (i.e., in Healthcare Facility or outside the healthcare facility)and also the number of antenatal visits they attended during the pregnancy. A mother that had four or more visits during the pregnancy was considered to have had adequate number of visits and those who did not attend at all or attended for less than four times were considered not to have had adequate attendance. Information was also collected on the socio-economic and demographic characteristics of the women.
\end{abstract}

The data analyzed consisted of 17,635 women aged 15-49 years who had a live birth within the five years preceding the survey Stata 12 computer software was used to carry outdataanalyses.Data analyses wereatunivariate, bivariate andmultivariate levels. Due to the dichotomous nature of the outcome variable (i.e., whether a child was delivered in a healthcare facility or not; coded as $(1,0)$ ), the multivariate analyses technique used is Binary Logistic Regression, and Likelihood Ratio (LR) statistical test of significance was applied.

Results from bivariate analysis indicated that the background (underlying) factors of the women (i.e., age, children ever born, region of residence, educational level, wealth index status, and religion) all have 
significant association with the number of antenatal visits made by mothers during their last pregnancy $(\mathrm{P}<$ 0.001). Similarly, antenatal clinic attendance has significant relationship with delivery in healthcare facility ( $P$ $<0.001)$.

The binary logistic regression which includes all the six background variables and antennal clinic attendance (i.e., the proximate determinant) indicated a highly significant contribution to the model chi-square statistic. Women who had adequate number of antenatal clinic visits were about four times more likely to deliver their babies in healthcare facility than mothers who did not $(O R=4.4, P<0.001)$. The likelihood Ratio $(L R)$ test to determine the extent to which antenatal clinic attendance helped to explain the effect of the background variables on delivery in healthcare facilities also gave a highly significant result (chi-square $=891$ on 1 degree of freedom, $\mathrm{P}<0.001$ ). This means that antenatal clinic attendance is an important proximate determinant through which socioeconomic, demographic and cultural factors influence Nigerian women delivery in healthcare facilities.

We conclude therefore that policies and programs targeted at encouraging Nigerian pregnant women to attend adequately antenatal clinics will also increase the prevalence of their delivery in healthcare facilities, thereby reducing the risk of maternal and infant mortality.

Keywords: Underlying Factors, Antenatal Clinic Attendance, Proximate Determinants, Healthcare Facility Delivery, Nigeria

\section{INTRODUCTION}

Maternal morbidity and mortality remains a challenge despite several global initiatives in reversing the trend. It is estimated that more than half million maternal deaths occur worldwide. The highest ratio is reported in Sub-Saharan Africa. It has been observed over time that most delivery is taking place outside established modern healthcare facility (whether public or private). A nation's development depends on the health status of its people and health is a basic human right of everybody everywhere. Accessibility to health care has a large socio-economic benefit whereas ill health has a grave effect on productivity. It is, therefore, not too surprising that Nigeria has one of the world's poorest maternal and child mortality rates and ratios. In order to reduce Nigeria's maternal and infant mortality rates, Nigerian mothers must intensify their utilization of modern healthcare facility for delivery. It is then that government can develop and implement appropriate and relevant policies that will produce the desired results.

Worldwide, there has been a significant drop in the number of women dying from pregnancy and childbirth. However, Africa still lags behind other parts of the world in making childbirth safe and the conditions in subSaharan Africa remain at emergency levels. In the 1990s, while the maternal death rate was as high as 1,100 per 100,000 live births in Nigeria, 600 in India, about 400 in Kenya, it was only 10, 12 and 17 for Italy, Poland and US respectively (World Bank Group, 2014). By the year 2010, while appreciable reduction has been achieved in other countries, Nigeria still ranks high among the countries with high maternal mortality due to low utilization of modern healthcare facilities (WHO, 2008). Recent findings by the World Bank Group (2014) indicate that maternal mortality in India is as low as 200 per 100,000 live births, 21 in United States, 4 in Italy and only 5 in Poland. In a recent report by the United Nations Funds for Population Activities (UNFPA, 2007), Nigeria is said to account for over 14 per cent of the World's maternal deaths. At about 145 of such deaths per day, this figure is outrageously high and unacceptable, if we consider that the figure translates to 576 deaths per 100,000 births and that Nigeria's population is just two per cent of the world's population.

An estimated 287,000 maternal deaths occurred globally in 2010 out of which 99.4 percent representing 285,300 occurred in developing countries and more than half of this proportion occurred in sub-Saharan Africa (World Bank, 2013). Nigeria accounts for about 10 percent of the Global Mortality Ratio putting the country in the class of second highest after India (Adamu, 2011). However, while virtually all developed countries have made appreciable progress in curbing the menace of maternal mortality, the appalling rates in Nigeria and other sub-Saharan African countries remain worrisome. South Asia, for example, succeeded in reducing maternal mortality from 620 per 100,000 live births in the 90s to 220 per 100,000 live births in 2010 (World Bank, 2013), Middle East Africa, North Africa, East Asia and Pacific have also reduced their maternal mortality ratios by more than 60 percent (World Bank, 2013).

Global efforts at reducing maternal deaths by engaging in the use of modern healthcare facilities and 
IJASOS- International E-Journal of Advances in Social Sciences, Vol. III, Issue 8, August 2017

disengaged from attending traditional birth homes have increased to save the life of mothers and children. Specifically, attempt to harmonize strategies were discussed in the World Conference on International Women's Year in Mexico in 1975, International Conference for Population and Development (ICPD) in Cairo (1994) and International Conference on Women in Beijing 1995, Hague Forum of 1999 and Millennium Development Goals (United Nations, 1994 and 2008; UN Women, 2011; UNFPA, 2013).

The use of modern healthcare services in developing countries have tended to demonstrate that people's acceptance or rejection of modern healthcare facilities is based on their perception of its effectiveness (Erasmus, 1961) and on how well it mesh with their traditional beliefs and practices concerning health and illness (Paul, Foste, 1976). People participate in Primary Healthcare Programmes to the extent that they experience the services as offering reliable solutions to what they perceive as health problems, including nutritional ones. The decision whether to use the services at the beginning of an illness, later, or even at all is calculated by weighing the anticipated benefits, in terms of opportunity cost, against the expected expenditure of time and money, and the personal abuse that these efforts may entail. The level of understanding on how people estimate factors on both sides of the equation relating costs to benefits is crucial to understanding the demand for primary healthcare services and, as a result, the strengths and weaknesses of the programmes.

In Nigeria, the choice to deliver outside modern healthcare infrastructure settings could be motivated by varying factors such as economic, social, physical, cultural or institutional. Outside the modern healthcare infrastructures setting, women can be assisted by an attendant who may be unskilled. This attendant could be a traditional birth attendant (TBA), village midwife, member of the family or neighbour. According to the Nigeria Demographic and Health Survey 2008, between 2003 and 2008, only 45 percent of Nigerian expectant mothers received adequate antenatal care from a skilled provider: doctors, nurses/midwives, auxiliary nurses/midwives, 28 percent of births were assisted by skilled provider and 25 percent of deliveries took place in modern healthcare facilities. Expectant mothers who cannot access these services, due to perceived challenges like cost, distance and trust, are left to use "alternatives" such as Traditional Birth attendance (TBA) services.

The antenatal period is an important time for collecting vital information that fosters women's health, wellbeing and survival of their infants. The international organizations, like United Nations Children Endowment Fund (UNICEF), the United Nations Fund for Population Activities (UNFPA) and the World Health Organization (WHO) recommended a minimum of four antenatal care visits during pregnancy. The prescribed minimum number of visits is expected to provide needed services for safe delivery, and it could be possible through proper intervention which include treatment of hypertension to prevent eclampsia, tetanus immunization, intermittent preventive treatment for malaria and distribution of insecticide-treated nets, prevention of mother-to-child transmission of HIV, and micronutrient supplementation, including information about danger signs during pregnancy and childbirth (UNICEF, 2011).An essential aspect of preserving health is to identify the factors that enable or prevent people from making healthy choices in either their life-style or their use of medical care and treatment, the underlying assumption being that behaviour is best understood in terms of an individual's perception of their social environment (Tipping and Segall, 1995). When individuals make decisions in relation to their health, they weigh up the potential risks or benefits of a particular behaviour.

\section{OBJECTIVE}

The main objective of the study is to determine if antenatal clinic attendance constitutes a medium (i.e., a proximate determinant) through which socioeconomic, demographic and cultural characteristics of women influence their decision to deliver their babies in modern healthcare facilities or outside of it. It is predicated on the assumption that these characteristics of women determine whether or not they attend antenatal clinics during pregnancy and that those who attend adequate number of times are more likely to deliver their babies in modern healthcare facilities than those who did not attend or attended for inadequate number of times.

\section{METHOD}

The study used quantitative data from the 2008 Nigeria Demographic and Health Surveys (NDHS). In all, a total sample of 33,385 women aged 15-49 years and 15,486 men aged 15-59 were interviewed using a structured questionnaire. For the purpose of this study, a sub-sample of 17,635 (weighted) population consisting women aged 15-49 years whose recent delivery occurred in the five years preceding the survey was utilized based on the focus of the study. This represents a total number of women (aged 15 to 49 years) in the reproductive age group as at the time of the study, that had given birth. Mothers were asked to indicate where they delivered their last babies (i.e., in Healthcare Facility or outside the healthcare facility) and also the number of antenatal visits they attended during the pregnancy. A mother that had four or more visits 
during the pregnancy was considered to have had adequate number of visits and those who did not attend at all or attended for less than four times were considered not to have had adequate attendance. Information was also collected on the socio-economic and demographic characteristics of the women. The data were analyzed using Stata 12 computer software The level of analyses involved Univariate, Bivariate and Multivariate analyses. Due to the dichotomous nature of the outcome variable (i.e., whether a child was delivered in a healthcare facility or not; coded as $(1,0)$ ), the multivariate analyses technique used is Binary Logistic Regression, and Likelihood Ratio (LR) statistical test of significance was applied.

\section{RESULTS}

Table 1 presents the background characteristics of women who delivered at least a child during the 5 years period prior to the survey. The distribution shows highest proportions of women who were in the age group 35 years and above (27\%) followed by women in the age group 25-29 (26.6\%). Information on the women wealth index reveals that a large proportion of the women (about 45 percent) in the country are poor.In addition, Table 1, also presents the percent distribution of live births according to the proximate determinants, that is, number of antenatal visits. However, the Table shows that 55percent of mothers reported to have had adequate antenatal clinic attendance having made four or more antenatal visits.

Table 1: Percentage Distribution of Women by Selected Socioeconomic and Antenatal Visits

\begin{tabular}{|c|c|c|}
\hline Variables & Frequency & Percentage \\
\hline Current Age & (N) & (\%) \\
\hline Less than 20 & 1,225 & 6.94 \\
\hline $20-24$ & 3,454 & 19.56 \\
\hline $25-29$ & 4,700 & 26.61 \\
\hline $30-34$ & 3,516 & 19.91 \\
\hline $35+$ & 4,765 & 26.98 \\
\hline \multicolumn{3}{|l|}{ Children Ever Born } \\
\hline 1 Child & 2,985 & 17.28 \\
\hline 2-3 Children & 5,526 & 31.99 \\
\hline 4-6 Children & 5,556 & 32.17 \\
\hline 7+ Children & 3,206 & 18.56 \\
\hline \multicolumn{3}{|l|}{ Region } \\
\hline North Central & 2,491 & 14.42 \\
\hline North east & 2,704 & 15.65 \\
\hline North west & 5,244 & 30.36 \\
\hline South east & 1,560 & 9.03 \\
\hline South west & 3,022 & 17.50 \\
\hline South south & 2,252 & 13.04 \\
\hline \multicolumn{3}{|l|}{ Educational Level } \\
\hline No education & 7,829 & 45.33 \\
\hline Primary & 3,932 & 22.76 \\
\hline Secondary & 4,481 & 25.94 \\
\hline Higher & 1,031 & 5.97 \\
\hline \multicolumn{3}{|l|}{ Wealth Index } \\
\hline Poorest & 3,963 & 22.94 \\
\hline Poorer & 3,834 & 22.19 \\
\hline Middle & 3,283 & 19.01 \\
\hline Richer & 3,153 & 18.25 \\
\hline Richest & 3,040 & 17.60 \\
\hline \multicolumn{3}{|l|}{ Religion } \\
\hline Christianity & 7,561 & 44.02 \\
\hline Islam & 9,322 & 54.28 \\
\hline Traditional Religion & 293 & 1.71 \\
\hline \multicolumn{3}{|l|}{ Antenatal Visits } \\
\hline Less than 4 visits & 7,787 & 45.48 \\
\hline 4 or more visits & 9,335 & 54.53 \\
\hline
\end{tabular}

Source: Computed by the Researcher from 2008 NDHS (2017) 
Table 2 shows the results of the bivariate association of the background variables and a proximate determinant (i.e, antenatal visits) and the place of delivery made by mothers during the pregnancy of their last children. The results indicated that all the background variables and the proximate determinant had significant bivariate association with place of delivery $(P=0.000$ in all cases). For example, the higher the level of education of the woman, the more likely that she made adequate number of antenatal visits at the place of delivery. It is a similar relationship for age of the mother. The older the woman, the more likely she adequately attended antenatal clinics and deliver at health facility, except that both attendance and delivery at health facility declined among women who were older than 35 years. For wealth status, the richer a woman the more likely she would adequately attend antenatal clinic and deliver at health facility. However, the greater the number of children a woman ever born, the less likely she would make adequate antenatal clinic attendance and also make delivery at health facility. Also, mothers in Southern regions of the country made greater number of antenatal visits than the mothers in the Northern regions and invariably affect their deliver at health facility. Christians' mothers made both more adequate visits and delivery at health facility than mothers of other religions.

Table 2: Bivariate Association of Socio-Economic and Demographic Characteristics and Antenatal Visits with Place of Delivery

\begin{tabular}{|c|c|c|c|c|}
\hline Variables & $\begin{array}{l}\text { Delivery in a health } \\
\text { Facility }\end{array}$ & $\begin{array}{l}\text { Did not deliver in a Health } \\
\text { Facility }\end{array}$ & $\begin{array}{l}\text { Chi-Square } \\
\text { Value }\end{array}$ & P-Value \\
\hline \multicolumn{5}{|l|}{ Current Age } \\
\hline Less than 20 & $265 \quad(23.28)$ & $875 \quad(76.72)$ & & \\
\hline $20-24$ & $\begin{array}{ll}1,008 & (30.33)\end{array}$ & $\begin{array}{ll}2,315 & (69.67) \\
\end{array}$ & & \\
\hline $25-29$ & $\begin{array}{ll}1,852 & (40.27) \\
\end{array}$ & $\begin{array}{ll}2,747 & (59.73) \\
\end{array}$ & & \\
\hline $30-34$ & (42.45) & $2,034 \quad(57.55)$ & & \\
\hline $35+$ & $(36.55)$ & $2,939 \quad 63.45)$ & 227.2052 & 0.0000 \\
\hline \multicolumn{5}{|c|}{ Children Ever Born } \\
\hline 1 Child & $\begin{array}{ll}1,388 & (46.58) \\
\end{array}$ & $\begin{array}{ll}1,592 & (53.42) \\
\end{array}$ & & \\
\hline 2-3 Children & $\begin{array}{ll}2,306 & (41.81) \\
\end{array}$ & $\begin{array}{ll}3,210 & (58.19) \\
\end{array}$ & & \\
\hline 4-6 Children & $\begin{array}{ll}1,947 & (35.16)\end{array}$ & $\begin{array}{ll}3,591 & (64.84) \\
\end{array}$ & & \\
\hline $7+$ Children & $\begin{array}{ll}677 & (21.21) \\
\end{array}$ & $\begin{array}{ll}2,515 & (78.79) \\
\end{array}$ & 534.4931 & 0.0000 \\
\hline \multicolumn{5}{|l|}{ Reaion } \\
\hline North Central & $(42.63)$ & $\begin{array}{ll}1,424 & (57.37)\end{array}$ & & \\
\hline North East & $\begin{array}{ll}377 & (13.94)\end{array}$ & $\begin{array}{ll}2,325 & (86.06) \\
\end{array}$ & & \\
\hline North West & $(09.43)$ & $\begin{array}{ll}4,727 & (90.57)\end{array}$ & & \\
\hline South East & $(74.34)$ & $400 \quad(25.66)$ & & \\
\hline South West & $(70.63)$ & $\begin{array}{ll}886 & (29.37) \\
\end{array}$ & & \\
\hline South south & $(49.00)$ & $\begin{array}{ll}1,146 & (51.00)\end{array}$ & 5015.2651 & 0.0000 \\
\hline \multicolumn{5}{|c|}{ Educational Level } \\
\hline No Educatiion & $(10.68)$ & $\begin{array}{ll}6.969 & (89.32)\end{array}$ & & \\
\hline Primary & $(40.46)$ & $\begin{array}{ll}2,336 & (59.54) \\
\end{array}$ & & \\
\hline Secondary & $(66.41)$ & $\begin{array}{ll}1,502 & (33.59)\end{array}$ & & \\
\hline Higher & $(90.15)$ & $\begin{array}{ll}101 & (09.85)\end{array}$ & 5383.7832 & 0.0000 \\
\hline \multicolumn{5}{|l|}{ Wealth Index } \\
\hline Poorest & $(07.76)$ & $\begin{array}{ll}3,645 & (92.24) \\
\end{array}$ & & \\
\hline Poorer & $(16.51)$ & $3,192 \quad(83.49)$ & & \\
\hline Middle & $(34.50)$ & $\begin{array}{ll}2,147 & (65.50)\end{array}$ & & \\
\hline Richer & $(57.69)$ & 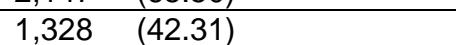 & & \\
\hline Richest & $\begin{array}{ll}2,438 & (80.37)\end{array}$ & $595 \quad(19.63)$ & 5306.6539 & 0.0000 \\
\hline \multicolumn{5}{|l|}{ Religion } \\
\hline Christian & $(57.26)$ & $\begin{array}{ll}3,225 & (42.74) \\
\end{array}$ & & \\
\hline Islam & $(20.70)$ & $\begin{array}{ll}7,369 & (79.30)\end{array}$ & & \\
\hline Traditionalist & $(17.89)$ & $241 \quad(82.11)$ & 2493.7312 & 0.0000 \\
\hline \multicolumn{5}{|c|}{ Antenatal Visits } \\
\hline Less than 4 & $\begin{array}{ll}1,584 & (47.74) \\
\end{array}$ & $7,739 \quad(52.26)$ & & \\
\hline 4 or More & $(60.37)$ & $\begin{array}{ll}3,085 & (39.63) \\
\end{array}$ & 5040.8178 & 0.0000 \\
\hline
\end{tabular}

Source: Computed by the Researcher from 2008 NDHS (2017) 
Table 3 shows the results of the bivariate association of the background variables with the number of antenatal visits made by mothers during the pregnancy of their last children. The results indicated that all the background variables had significant bivariate association with antenatal visits $(P=0.000$ in all cases). For example, the higher the level of education of the woman, the more likely that she made adequate number of antenatal visits. It is a similar relationship for age of the mother. The older the woman, the more likely she adequately attended antenatal clinics, except that attendance declined among women who were older than 35 years. For wealth status, the richer a woman the more likely she would adequately attend antenatal clinic. However, the greater the number of children a woman ever born, the less likely she would make adequate antenatal clinic attendance. Also, mothers in Southern regions of the country made greater number of antenatal visits than the mothers in the Northern regions. Christians mothers made more adequate visits than mothers of other religions.

Table 3: Bivariate Association of Socio-Economic and Demographic Characteristics with Number of Antenatal Visits

\begin{tabular}{|c|c|c|c|c|c|c|}
\hline Variables & \multicolumn{2}{|c|}{4 or More } & \multicolumn{2}{|c|}{ Less than 4} & \multirow[t]{2}{*}{ Chi-Square Value } & \multirow[t]{2}{*}{ P-Value } \\
\hline Current Age & & & & & & \\
\hline Less than 20 & 339 & $(29.80)$ & 798 & $(70.20)$ & & \\
\hline $20-24$ & 1,335 & $(40.50)$ & 1,961 & $(59.50)$ & & \\
\hline $25-29$ & 2,260 & $(49.48)$ & 2,307 & $(50.52)$ & & \\
\hline $30-34$ & 1,797 & $(51.10)$ & 1,720 & $(48.91)$ & & \\
\hline $35+$ & 2,057 & $(44.65)$ & 2,550 & $(55.35)$ & 273.4866 & 0.0000 \\
\hline \multicolumn{7}{|l|}{ Children Ever Born } \\
\hline 1 Child & 1,512 & $(50.92)$ & 1,458 & (49.09) & & \\
\hline 2-3 Children & 2,712 & $(49.57)$ & 279 & (50.42) & & \\
\hline 4-6 Children & 2,540 & $(46.08)$ & 2,972 & $(53.91)$ & & \\
\hline $7+$ Children & 1,024 & $(32.27)$ & 2,148 & $(67.73)$ & 418.8354 & 0.0000 \\
\hline \multicolumn{7}{|l|}{ Region } \\
\hline North Central & 1,205 & $(48.75)$ & 1,267 & $(51.25)$ & & \\
\hline North East & 882 & (32.81) & 1,806 & $(67.20)$ & & \\
\hline North West & 1,094 & $(21.13)$ & 4,083 & $(78.86)$ & & \\
\hline South East & 957 & $(61.66)$ & 595 & $(38.34)$ & & \\
\hline South West & 2,447 & $(81.66)$ & 550 & (18.34) & & \\
\hline South south & 1,202 & $(53.73)$ & 1,035 & $(46.26)$ & 5362.1804 & 0.0000 \\
\hline \multicolumn{7}{|l|}{ Educational Level } \\
\hline No Education & 1,734 & $(22.40)$ & 6,007 & $(77.60)$ & & \\
\hline Primary & 2,119 & $(54.19)$ & 1,791 & $(45.81)$ & & \\
\hline Secondary & 3,096 & (69.56) & 1,355 & $(30.44)$ & & \\
\hline Higher & 838 & $(82.15)$ & 182 & $(17.86)$ & 5296.1017 & 0.0000 \\
\hline \multicolumn{7}{|l|}{ Wealth Index } \\
\hline Poorest & 627 & (15.94) & 3,306 & $(84.07)$ & & \\
\hline Poorer & 1,106 & $(29.12)$ & 2,691 & $(70.87)$ & & \\
\hline Middle & 1,568 & $(48.22)$ & 1,683 & $(51.78)$ & & \\
\hline Richer & 2,025 & $(64.86)$ & 1,097 & (35.14) & & \\
\hline Richest & 2,461 & $(81.56)$ & 557 & $(18.44)$ & 5448.9630 & 0.0000 \\
\hline \multicolumn{7}{|l|}{ Religion } \\
\hline Christian & 4,598 & $(61.27)$ & 2,907 & $(38.73)$ & & \\
\hline Islam & 3,056 & $(33.10)$ & 6,176 & (66.89) & & \\
\hline Traditional Religion & 96 & (32.81) & 196 & (67.19) & 2793.6142 & 0.0000 \\
\hline
\end{tabular}

Source: Computed by the Researcher from 2008 NDHS (2017)

Table 4 shows the results from the logistic regression for place of delivery controlling for selected background variables to show which of the background variables demonstrate a significant independent 
relationship with the outcome variable. Only two variables were found not to have a significant effect on the place of delivery.

Only the mothers who were 30-34 and 35 years and older had significantly higher use of healthcare facility for delivery than mothers who were less than 20 years $(O R=1.503$ and $1.686, P=0.001$ respectively). The findings also showed that the higher the number of children ever born, the less likely she would deliver in health facility. Women with level of education were more likely to utilize health facility for delivery when compared to women with no education. The odds ratios or chance that a woman would deliver her baby in a healthcare facility increases with increase in odd ratios. The odds ratios were 2.0, 3.5 and 8.5 for primary, secondary and post-secondary education respectively. All the odd ratios were significantly different at $(\mathrm{P}<0.001)$. Hence, the log likelihood results obtained for all the analysis when the proximate was not included was -7179 and $($ LR 1$)=7879$.

Table 4: Binary Logistic Regression Model for Place of Delivery Controlling for Selected Socio-Economic Characteristics

\begin{tabular}{|c|c|c|c|c|}
\hline Variables & Odd Ratio & P-Value & STD Error & Confidence Interval (95\%) \\
\hline \multicolumn{5}{|l|}{ Current Age } \\
\hline Less than 20 & R.C & & & \\
\hline $20-24$ & 1.008 & 0.938 & 0.101 & $(0.828,1.228)$ \\
\hline $25-29$ & 1.265 & 0.024 & 0.132 & $(1.031,1.552)$ \\
\hline $30-34$ & 1.503 & 0.000 & 0.171 & $(1.203,1.877)$ \\
\hline $35+$ & 1.686 & 0.000 & 0.200 & $(1.336,2.128)$ \\
\hline \multicolumn{5}{|l|}{ Children Ever Born } \\
\hline 1 Child & R.C & & & \\
\hline 2-3 Children & 0.744 & 0.000 & 0.051 & $(0.651,0.851)$ \\
\hline 4-6 Children & 0.622 & 0.000 & 0.049 & $(0.532,0.727)$ \\
\hline $7+$ Children & 0.543 & 0.000 & 0.054 & $(0.446,0.660)$ \\
\hline \multicolumn{5}{|l|}{ Region } \\
\hline North Central & R.C & & & \\
\hline North East & 0.425 & 0.000 & 0.029 & $(0.371,0.486)$ \\
\hline North West & 0.204 & 0.000 & 0.015 & $(0.175,0.236)$ \\
\hline South East & 1.628 & 0.000 & 0.133 & $(1.387,1.910)$ \\
\hline South West & 1.358 & 0.000 & 0.094 & $(1.184,1.556)$ \\
\hline South south & 0.490 & 0.000 & 0.034 & $(0.427,0.562)$ \\
\hline \multicolumn{5}{|l|}{ Educational Level } \\
\hline No Education & R.C & & & \\
\hline Primary & 2.048 & 0.000 & 0.119 & $(1.827,2.296)$ \\
\hline Secondary & 3.518 & 0.000 & 0.229 & $(3.097,3.997)$ \\
\hline Higher & 8.509 & 0.000 & 1.083 & $(6.630,10.920)$ \\
\hline \multicolumn{5}{|l|}{ Wealth Index } \\
\hline Poorest & R.C & & & \\
\hline Poorer & 1.780 & 0.000 & 0.132 & $(1.538,2.059)$ \\
\hline Middle & 3.045 & 0.000 & 0.221 & $(2.641,3.511)$ \\
\hline Richer & 5.792 & 0.000 & 0.439 & $(4.993,6.720)$ \\
\hline Richest & 10.833 & 0.000 & 0.967 & $(9.094,12.906)$ \\
\hline \multicolumn{5}{|l|}{ Reliqion } \\
\hline Christian & R.C & & & \\
\hline Islam & 0.915 & 0.133 & 0.535 & $(0.817,1.027)$ \\
\hline Traditional Religion & 0.447 & 0.000 & 0.076 & $(0.320,0.624)$ \\
\hline
\end{tabular}

Source: Computed by the Researcher from 2008 NDHS (2017)

$\begin{array}{llll}\text { Number of observation } & =17514 & \text { LR chi } 2(21)=7879 \text { Prob }>\text { chi } 2=0.0000 \\ \text { Pseudo R2 } & =0.3546 & \text { Log likelihood }=-7169\end{array}$ 
Table 5 shows the results from the binary logistic regression analysis for Place of delivery controlling for selected background characteristics and antenatal clinic visits. The odd of delivering in health facility was 9.7 times as likely for those women who had adequate number of antenatal clinic visits than those who did not.

Table 5: Binary Logistic Regression Model for Place of Delivery Controlling for Selected Socio-Economic Characteristics and Number of Antenatal Visits

\begin{tabular}{|c|c|c|c|c|}
\hline Variables & Odd Ratio & P-Value & STD Error & Confidence Interval (95\%) \\
\hline \multicolumn{5}{|l|}{ Current Age } \\
\hline Less than 20 & R.C & & & \\
\hline $20-24$ & 0.898 & 0.310 & 0.095 & $(0.729,1.105)$ \\
\hline $25-29$ & 1.075 & 0.510 & 0.118 & $(0.867,1.333)$ \\
\hline $30-34$ & 1.260 & 0.053 & 0.151 & $(0.997,1.592)$ \\
\hline $35+$ & 1.421 & 0.005 & 0.177 & $(1.112,1.815)$ \\
\hline \multicolumn{5}{|l|}{ Children Ever Born } \\
\hline 1 Child & R.C & & & \\
\hline 2-3 Children & 0.750 & 0.000 & 0.053 & $(0.653,0.861)$ \\
\hline 4-6 Children & 0.618 & 0.000 & 0.051 & $(0.526,0.727)$ \\
\hline $7+$ Children & 0.574 & 0.000 & 0.060 & $(0.468,0.704)$ \\
\hline \multicolumn{5}{|l|}{ Region } \\
\hline North Central & R.C & & & \\
\hline North East & 0.436 & 0.000 & 0.031 & $(0.379,0.502)$ \\
\hline North West & 0.294 & 0.000 & 0.024 & $(0.251,0.344)$ \\
\hline South East & 1.657 & 0.000 & 0.139 & $(1.406,1.953)$ \\
\hline South West & 1.227 & 0.004 & 0.087 & $(1.067,1.411)$ \\
\hline South south & 0.576 & 0.000 & 0.042 & $(0.499,0.664)$ \\
\hline \multicolumn{5}{|l|}{ Educational Level } \\
\hline No Education & R.C & & & \\
\hline Primary & 1.545 & 0.000 & 0.094 & $(1.371,1.740)$ \\
\hline Secondary & 2.528 & 0.000 & 0.170 & $(2.216,2.884)$ \\
\hline Higher & 5.743 & 0.000 & 0.743 & $(4.457,7.401)$ \\
\hline \multicolumn{5}{|l|}{ Wealth Index } \\
\hline Poorest & R.C & & & \\
\hline Poorer & 1.385 & 0.000 & 0.109 & $(1.186,1.616)$ \\
\hline Middle & 2.047 & 0.000 & 0.157 & $(1.762,2.380)$ \\
\hline Richer & 3.546 & 0.000 & 0.284 & $(3.031,4.148)$ \\
\hline Richest & 6.107 & 0.000 & 0.569 & $(5.087,7.331)$ \\
\hline \multicolumn{5}{|l|}{ Religion } \\
\hline Christian & R.C & & & \\
\hline Islam & 0.956 & 0.448 & 0.057 & $(0.850,1.075)$ \\
\hline Traditional Religion & 0.462 & 0.000 & 0.082 & $(0.326,0.653)$ \\
\hline \multicolumn{5}{|l|}{ Antenatal Visits } \\
\hline Less than 4 & R.C & & & \\
\hline 4 or More & 9.702 & 0.000 & 0.755 & $(8.329,11.302)$ \\
\hline
\end{tabular}

Source: Computed by the Researcher from 2008 NDHS (2017)

$\begin{array}{lll}\text { Number of observation } & =17403 & \text { LR chi } 2(23)=8987 \text { Prob }>\text { chi } 2=0.0000 \\ \text { Pseudo R2 } & =0.4069 & \text { Log likelihood }=-6549\end{array}$

The following background variables still maintained significant independent (indirect) effects on the dependent variable, despite the presence of the proximate variable. They are age of mother, children ever born, region, women's education, wealth index, religion. The fact that most of these variables had previously shown significant direct relationship with the proximate variables is an indication that they influence women's delivery in health facilities not only through attendance of antenatal clinics as a proximate variables, but also through some other proximate variables that were considered or captured in the model. Increase in mother's level of education and wealth status corresponds to increased use of modern healthcare facilities for 
delivery. Hence, from the results obtained for all the analysis which are not shown yet implied that the log likelihood of the first analysis when the proximate was not included (LR 1) was 7879 and from the log likelihood when the proximate was included (LR 2) was 8987. The difference (LR2 - LR1) = 1108 (on 2 degrees of freedom; $P=0.0000$ ). This is highly significant. Therefore we conclude that the proximate variable (Antenatal Visits) had significantly helped to explain the association (indirect effects) of the socioeconomic and demographic (background) variables on health facility for delivery by mothers in Nigeria.

\section{DISCUSSION / CONCLUSION}

The proximate determinant used significantly helped to explain the indirect effects of the background variables on modern healthcare delivery. Mothers who had adequate antenatal clinic attendance delivered their babies in healthcare facilities more than those mothers who did not attend or whose attendance were inadequate. We therefore conclude that antenatal clinic attendance is an important proximate factor through which the socioeconomic, demographic and cultural factors influence mothers to deliver their babies in modern healthcare facilities. Hence, policies that are targeted to ensure adequate antenatal clinic attendance by pregnant women on their healthcare services utilization would go a long way in increasing the level of utilization of healthcare facilities for delivery in Nigeria.

\section{LIMITATIONS OF THE STUDY}

The author recognizes the existence of some limitations of this study, and suggests that these limitations be viewed as opportunities for future research and reflections. Hence, future studies may attempt to replicate and provide more insights to this research in different settings. The following are some of the limitations of the study: The 2008 (NDHS) data utilized were nationally representative data, but there were limitations as predetermined by the data. Like other secondary data, the 2008 NDHS data were not exclusive in the sense that they could not include all possible variables which may influence the health care utilization behaviour of Nigerian women. Such variables that related to the quality of healthcare received by women include, number and types of available service facilities in each locality, number and quality of available modern healthcare providers, quality of infrastructure available at the government and private health facilities, and information on other traditional healthcare providers that women may be consulting.

\section{RECOMMENDATION}

Policies and programs that ensure that all pregnant women have adequate number of antenatal clinic attendance should be put in place. This includes communication programs that enlighten women on the need for adequate antenatal clinic attendance during pregnancy and delivery in healthcare facilities where they can receive health professional assistance for safe delivery.

Stakeholders must also ensure the availability of such services and should be well targeted, by placing special focus on those categories of women who had been identified in this study as very deficient in their antenatal clinic attendance. They include rural mothers, very young mothers (i.e., under 20 years old), mothers with little or no education, poor women, women of high parity, unmarried mothers, and women who reside in the northern regions of the country, particularly the north east and the north west.

\section{ACKNOWLEDGEMENT}

We would like to sincerely and deeply appreciate Covenant University for the financial sponsorship of the conference during the paper presentation before the final publication of my paper.

\section{REFERENCE LIST}

Adamu Hauwa Suleiman (2011). Utilization of Maternal Health Care Services in Nigeria: An Analysis of Regional Differences in the Patterns and Determinants of Maternal Health Care Use.

Erasmus C.(1961).Man takes control: cultural development and American aid. Minneapolis, Minn, USA: University of Minnesota Press.

Fosu, G. B. (1994). Childhood morbidity and health services utilization: cross-national comparisons of userrelated factors from DHS data. Social Science and Medicine, 38, 1209-1220.

Mosley WH, Chen LC. (1984) An analytic framework for the study of child survival in developing countries. Population and Development Review; 1984, 10:25-45. 
Orubuloye, I. O. (2003).Disease, Illness and Society. Centre for Population and Health Resources, Ado-Ekiti, Nigeria, pp. 1-26.

Paul, B.K., \& D.J. Rumsey. 2002. Utilization of health facilities and trained birth attendants for childbirth in rural Bangladesh: An empirical study. Social Science and Medicine 54:1755-1765.

Tipping, G., Segall, M. (1995). Healthcare Seeking Behavior in Developing Countries: An Annotated Bibliography and Literature Review.

United Nations (1994). Report of the International Conference on Population and Development, Cairo, 5-13, September 1994.

UNFPA (2007).Men at work.World Population Day document.Retrieved September 10, from http://www.unfpa.org.

World Health Organization (2008), Factsheet, Maternal Mortality, Department of Making Pregnancy Safer.

World Bank Group (2014). Maternal Mortality Ratio, Modelled Estimate per 100,000 live births. World Bank Group 2014 http://data.worldbank.org/indicator/SH.STA.MMRT

World Health Organization (2012). Trends in maternal mortality: 1990 to 2010 (WHO, UNICEF, UNFPA and The World Bank estimates).World HealthOrganization, Geneva, Switzerland. 2012. ISBN: 978924 1503631.

WHO.Annual Report 2007, Department of Making Pregnancy Safer. WHO, 2008, Geneva/Switzerland

WHO, UNICEF, UNFPA and the World Bank, Trends in Maternal Mortality: 1990 to 2010, WHO, Geneva, 2012.

World Bank (2013). World Development Indicators. International Bank for Reconstruction and Development. The World Bank, Washington. 